\title{
Changes in COVID-19 outbreak severity and duration in long-term care facilities following vaccine introduction, England, November 2020 to June 2021
}

\author{
Rebecca Giddings ${ }^{1}$, Maria Krutikov ${ }^{1}$, Tom Palmer ${ }^{2}$, Christopher Fuller $^{1}$, Borscha Azmi ${ }^{1}$, Madhumita Shrotri $^{1}$, Aidan Irwin-Singer ${ }^{3}$ \\ , Gokhan Tut 4 , Paul Moss ${ }^{4}$, Andrew Copas ${ }^{2}$, Laura Shallcross ${ }^{1}$ \\ 1. UCL Institute of Health Informatics, London, United Kingdom \\ 2. UCL Institute for Global Health, London, United Kingdom \\ 3. Department of Health and Social Care, United Kingdom \\ 4. Institute of Immunology and Immunotherapy, University of Birmingham, Birmingham, United Kingdom
}

Correspondence: Rebecca Giddings (rebeccagiddings@nhs.net)

Citation style for this article:

Giddings Rebecca, Krutikov Maria, Palmer Tom, Fuller Christopher, Azmi Borscha, Shrotri Madhumita, Irwin-Singer Aidan, Tut Gokhan, Moss Paul, Copas Andrew, Shallcross Laura. Changes in COVID-19 outbreak severity and duration in long-term care facilities following vaccine introduction, England, November 2020 to June 2021. Euro Surveill. 2021;26(46):pii=2100995. https://doi.org/10.2807/1560-7917.ES.2021.26.46.2100995

We describe the impact of changing epidemiology and vaccine introduction on characteristics of COVID19 outbreaks in 330 long-term care facilities (LTCF) in England between November 2020 and June 2021. As vaccine coverage in LTCF increased and national incidence declined, the total number of outbreaks and outbreak severity decreased across the LTCF. The number of infected cases per outbreak decreased by $80.6 \%$, while the proportion of outbreaks affecting staff only increased. Our study supports findings of vaccine effectiveness in LTCF.

\section{Introduction}

Long-term care facilities (LTCF) have been disproportionately affected by the coronavirus disease (COVID-19) pandemic, with residents particularly at risk of severe outcomes [1]. English LTCF have been impacted by three waves of severe acute respiratory syndrome coronavirus 2 (SARS-CoV-2) infections, with changes in disease control measures and epidemiology of infection over successive waves. The aim of this study was to describe how the changing epidemiology and vaccination introduction have affected COVID-19 outbreak characteristics, including outbreak duration and severity, in LTCF to inform revaccination strategies and the implementation of non-pharmaceutical interventions to prevent transmission.

\section{Identifying outbreaks in long-term care facilities}

The VIVALDI study, established in May 2020, is a prospective cohort study of LTCF staff and residents from a range of providers in England which provide care to adults aged over 65 years, with participant follow-up for up to 18 months [2]. The PCR and lateral flow device
(LFD) results from March 2020 onwards were linked at individual and LTCF level (see Supplement for data linkage methodology).

Within this cohort, we explored the characteristics of COVID-19 outbreaks during different time periods to account for vaccination roll-out and COVID-19 pandemic waves in England: (i) 1 November 2020 to 31 December 2020 (second wave, pre-vaccination), (ii) 1 January 2021 to 28 February 2021 (second wave, low first dose vaccination coverage), (iii) 1 March 2021 to 30 April 2021 (second wave, high first dose vaccination coverage, low second dose vaccination coverage) and (iv) 1 May 2021 to 30 June 2021 (third wave, high first and second dose vaccination coverage).

We extracted LTCF characteristics from seven datasets (see Supplementary Table $\mathrm{S}_{1}$ ) and assessed them midway through each time period.

Long-term care facilities commenced regular SARSCoV-2 PCR testing of staff (weekly) and residents (monthly) in the whole facility in July 2020 in addition to whole-LTCF (staff and residents) testing during a COVID-19 outbreak [3]. In December 2020, additional LFD testing was introduced for staff (twice weekly) and increased staff and resident testing during an outbreak [4]. For this analysis, outbreaks were defined as two or more positive SARS-CoV-2 tests (PCR/LFD) in the same LTCF within a 14-day period and ended when no further positive tests were reported for 28 days following the last positive [5]. Outbreak severity markers were outbreak length (days), number of people infected and number of deaths confirmed as related to COVID-19 during the outbreak period (Supplementary Table S1). 
A large outbreak was defined as infection of at least one third of the LTCF staff and residents.

\section{Characteristics of long-term care facilities}

A total of 330 LTCF were included in the study, representing a mix of for-profit and not-for-profit LTCF across England (Table 1). The median number of staff per LTCF was 45 (interquartile range (IQR): 33-61, range: 1-156) across the time periods and the median number of residents was 36 (IQR: 26-48, range: 1-149). The majority of LTCF were medium-sized with 50-100 individuals (staff and residents) (range: 8-304) and had a care quality commission (CQC) rating of 'good'. Median first dose vaccination coverage per LTCF was consistently higher in residents than staff: $85.7 \%$ (IQR: 67.7-93.1) vs $57.4 \%$ (IQR: 39.9-75.6) between January and February 2021, with coverage rising to $90.3 \%$ in residents (IQR: $79.3-95.7)$ and $80.7 \%$ in staff (IQR: 72.0-87.5) between May and June 2021.

The mean number of PCR tests performed per LTCF remained relatively stable (252.8-299.3), whereas mean LFD numbers increased substantially from 10.9 (standard deviation (SD): 1.9) LFD tests per LTCF between November and December 2020 to a peak of 247.5 (SD: 12.9) between March and April 2021, reflecting LFD changes in testing policy in England. Test positivity was highest between January and February 2021 (Table 1), consistent with national SARS-CoV-2 incidence [6].

\section{COVID-19 outbreaks}

Between 1 November 2020 and 30 June 2021, there were 297 COVID-19 outbreaks across 330 LTCF, and 240 LTCF (73\%) experienced at least one outbreak (Table 2). The mean number of outbreaks per LTCF was 0.90 (SD: 0.037). Between November 2020 and February 2021, when first dose vaccination coverage was lowest (57.4\% and $85.7 \%$ of staff and residents, respectively, vaccinated mid-way through January and February 2021), over $50 \%$ of LTCF experienced a COVID-19 outbreak. By comparison, the proportion of LTCF experiencing outbreaks declined to 23/203 between March and April 2021, when over $75 \%$ of staff and over $85 \%$ of residents per LTCF had received first dose vaccination. The proportion further declined to $15 / 322$ between May and June 2021, when 64.1\% (IQR: 49.0-75.7) and 85.0\% (IQR: $71.9-92.0$ ) of staff and residents, respectively, had been fully vaccinated with two doses (Table 1 and Table 2).

During November and December 2020, 112/145 outbreaks in LTCF were mixed, i.e. among staff and residents, dropping to $84 / 114$ and $10 / 23$ in subsequent time-periods and down to 5/15 by May and June 2021 (Figure 1 and Figure 2). Conversely, the proportion of outbreaks affecting only staff increased over time from 20/145 between November and December 2020 before vaccination roll-out, to $9 / 23$ between March and April 2021, reaching 8/15 between May and June 2021. The proportion of outbreaks affecting only residents remained low compared to staff-only outbreaks, dropping to 8/114 between January and February 2021 and peaking at 4/23 between March and April 2021.

Outbreak severity decreased as LTCF vaccination coverage increased, with an $80.6 \%$ reduction in the number of infected cases per outbreak and a $45.9 \%$ reduction in outbreak duration when comparing outbreaks between November and December 2020 with outbreaks between May and June 2021 (Table 2). The mean number of individuals infected per outbreak was slightly higher in residents than staff throughout, except between May and June 2021. The mean proportion of the LTCF infected during an outbreak decreased from $17.6 \%$ (SD: 1.51) between November and December 2020 to 3.01\% (SD: 0.68) between May and June 2021, and was consistently higher in residents. The proportion of residents who died of COVID-19 or were infected with SARSCoV-2 during an outbreak decreased over the study period; less than $5 \%$ of residents died of COVID-19 in LTCF experiencing outbreaks after March 2021 (Figure 3 ) and the proportion of individuals infected per outbreak decreased when first dose vaccination coverage exceeded $25 \%$ (see Supplementary Figure S 1 and Table S3). There were no large outbreaks from March 2021 to the end of the study period (June 2021).

There was no substantial difference in results when outbreaks were considered to be over after 35 days without new positive tests vs 28 days (see Supplementary Table S2).

\section{Ethical statement}

Ethical approval was obtained from the South Central Hampshire B Research Ethics Committee (reference number: 20/SC/0238).

\section{Discussion}

From November 2020 to June 2021, as total LTCF vaccination coverage increased, the number of LTCF outbreaks and their severity decreased, with a concomitant increase in the proportion of staff-only outbreaks, while the attack rate per outbreak remained consistently higher for residents.

Our results suggest vaccination has had a major impact on the risk of LTCF outbreaks and supports evidence demonstrating vaccine effectiveness in LTCF residents and staff $[7,8]$. The change in outbreak characteristics may also be linked with broader policy changes (e.g. national lockdowns) and changing national incidence rates. Our study showed no clear effect following the emergence of more transmissible SARS-CoV-2 variants such as the Delta variant (Phylogenetic Assignment of Named Global Outbreak (Pango) lineage designation B.1.617.2), however, the last month of the study (June 2021) saw a slight increase in outbreak numbers relative to previous months, likely driven by increasing community incidence nationally [6]. 
TABLE 1

Baseline characteristics of included long-term care facilities with and without COVID-19 outbreaks across four time periods, England, November 2020-June $2021(\mathrm{n}=330)^{\mathrm{a}}$

\begin{tabular}{|c|c|c|c|c|c|c|c|c|}
\hline Characteristics & \multicolumn{2}{|c|}{$\begin{array}{l}\text { Time period } 1 \\
\text { Nov-Dec } 2020\end{array}$} & \multicolumn{2}{|c|}{$\begin{array}{l}\text { Time period } 2 \\
\text { Jan-Feb } 2021\end{array}$} & \multicolumn{2}{|c|}{$\begin{array}{l}\text { Time period } 3 \\
\text { Mar-Apr } 2021\end{array}$} & \multicolumn{2}{|c|}{$\begin{array}{l}\text { Time period } 4 \\
\text { May-Jun } 2021\end{array}$} \\
\hline Number of LTCF & \multicolumn{2}{|c|}{$n=270$} & \multicolumn{2}{|c|}{$n=210$} & \multicolumn{2}{|r|}{$\mathrm{n}=203$} & \multicolumn{2}{|r|}{$n=322$} \\
\hline Number per LTCF ${ }^{b}$ & Median & IQR & Median & IQR & Median & IQR & Median & IQR \\
\hline Staff & 43 & $2-58$ & 47 & $3-60$ & 48 & $35-63$ & 45 & $34-62(n=319)$ \\
\hline Residents & 38 & $\begin{array}{c}28-50 \\
(n=269)\end{array}$ & 38 & $29-51(n=209)$ & 36 & $\begin{array}{c}28-49 \\
(n=201)\end{array}$ & 32 & $23-45(n=320)$ \\
\hline Proportion per LTCF & Median & IQR & Median & IQR & Median & IQR & Median & IQR \\
\hline Female & 68.5 & $\begin{array}{l}61.7-74.1 \\
(\mathrm{n}=269)\end{array}$ & 69.0 & $\begin{array}{l}61.7-74 \cdot 3 \\
(\mathrm{n}=209)\end{array}$ & 68.9 & $\begin{array}{l}61.5-76.3 \\
(\mathrm{n}=201)\end{array}$ & 69.2 & $\begin{array}{l}62.3-76.7 \\
(\mathrm{n}=320)\end{array}$ \\
\hline Male & 31.5 & $\begin{array}{l}25.9-38.3 \\
(n=269)\end{array}$ & 31.0 & $\begin{array}{l}25.7-38.3 \\
(\mathrm{n}=209)\end{array}$ & 31.1 & $\begin{array}{c}23.7-38.5 \\
(\mathrm{n}=201)\end{array}$ & 30.8 & $\begin{array}{l}23.3-37.7 \\
(\mathrm{n}=320)\end{array}$ \\
\hline Aged $>80$ years & 75 & $\begin{array}{l}65.6-82.5 \\
(n=269)\end{array}$ & 74.2 & $\begin{array}{l}64.3-81.0 \\
(n=209)\end{array}$ & 73.5 & $\begin{array}{l}63.9-80.8 \\
(n=201)\end{array}$ & 71.4 & $\begin{array}{l}63.6-80 \\
(\mathrm{n}=320)\end{array}$ \\
\hline Beds for residents with dementia & 54.7 & $\begin{array}{c}49.6-76.9 \\
(n=50)\end{array}$ & 61.5 & $\begin{array}{c}50-90.9 \\
(\mathrm{n}=38)\end{array}$ & 59.6 & $\begin{array}{l}48.8-100 \\
(n=38)\end{array}$ & 63.7 & $\begin{array}{l}50-87.2 \\
(\mathrm{n}=70)\end{array}$ \\
\hline Staff vaccinated (first dose) & o & $0-0$ & 57.4 & $\begin{array}{c}39.9-75.6 \\
(\mathrm{n}=208)\end{array}$ & 76.3 & $\begin{array}{l}67.6-84.5 \\
(n=201)\end{array}$ & 80.7 & $\begin{array}{c}72.0-87.5 \\
(\mathrm{n}=318)\end{array}$ \\
\hline Residents vaccinated (first dose) & 0 & $0-0$ & 85.7 & $\begin{array}{l}67.7-93.1 \\
(\mathrm{n}=208)\end{array}$ & 88.0 & $\begin{array}{c}78.0-93.5 \\
(\mathrm{n}=201)\end{array}$ & 90.3 & $\begin{array}{c}79.3-95.7 \\
(\mathrm{n}=317)\end{array}$ \\
\hline Staff vaccinated (second dose) & 0 & $0-0$ & o & $0-0$ & o & $0-0$ & 64.1 & $\begin{array}{c}49.0-75.7 \\
(\mathrm{n}=318)\end{array}$ \\
\hline Residents vaccinated (second dose) & o & $0-0$ & o & $0-0$ & o & $0-0$ & 85.0 & $\begin{array}{c}71.9-92.0 \\
(\mathrm{n}=318)\end{array}$ \\
\hline Monthly turnover per LTCF $^{\mathrm{b}}$ & Mean & IQR & Mean & IQR & Mean & IQR & Mean & IQR \\
\hline Staff & 3.3 & $1.7-4.9(n=81)$ & 3.2 & $\begin{array}{l}1.6-5.0 \\
(n=60)\end{array}$ & 2.9 & $1.7-4.5(n=63)$ & 2.0 & $0-4.5(n=94)$ \\
\hline Resident & 6.5 & $\begin{array}{l}3.6-10.1 \\
(\mathrm{n}=81)\end{array}$ & 5.6 & $\begin{array}{l}3.5-7.7 \\
(\mathrm{n}=60)\end{array}$ & 6.0 & $\begin{array}{l}3.6-8.3 \\
(n=63)\end{array}$ & 7.9 & $\begin{array}{l}4.3-13.2 \\
(n=94)\end{array}$ \\
\hline \multirow{2}{*}{$\begin{array}{l}\text { LTCF size (number of staff plus number of } \\
\text { residents) }\end{array}$} & \multicolumn{2}{|c|}{ Total $n=269$} & \multicolumn{2}{|c|}{ Total $n=209$} & \multicolumn{2}{|c|}{ Total $n=201$} & \multicolumn{2}{|c|}{ Total $\mathrm{n}=317$} \\
\hline & $n$ & $\%$ & $\mathrm{n}$ & $\%$ & $\mathrm{n}$ & $\%$ & $\mathrm{n}$ & $\%$ \\
\hline Small $(<50)$ & 42 & 15.6 & 26 & 12.4 & 26 & 12.9 & 48 & 15.1 \\
\hline Medium $(50-100)$ & 148 & 55.0 & 111 & 53.1 & 105 & 52.2 & 175 & 55.2 \\
\hline Large (>100) & 79 & 29.4 & 72 & 34.5 & 70 & 34.8 & 94 & 29.7 \\
\hline \multirow[t]{2}{*}{ LTCF type } & \multicolumn{2}{|c|}{ Total $n=270$} & \multicolumn{2}{|c|}{ Total $n=210$} & \multicolumn{2}{|c|}{ Total $n=203$} & \multicolumn{2}{|c|}{ Total $n=322$} \\
\hline & $\mathrm{n}$ & $\%$ & $n$ & $\%$ & $n$ & $\%$ & $\mathrm{n}$ & $\%$ \\
\hline For-profit & 180 & 66.7 & 157 & 74.8 & 136 & 67.0 & 225 & 69.9 \\
\hline Not-for-profit & 59 & 21.9 & 27 & 12.9 & 43 & 21.2 & 60 & 18.6 \\
\hline Independent & 31 & 11.5 & 26 & 12.4 & 24 & 11.8 & 37 & 11.5 \\
\hline CQC rating & & al $n=269$ & & al $n=208$ & & al $n=201$ & & al $n=320$ \\
\hline & $\mathrm{n}$ & $\%$ & $n$ & $\%$ & $n$ & $\%$ & $\mathrm{n}$ & $\%$ \\
\hline Inadequate & 6 & 2.2 & 5 & 2.4 & 2 & 1.0 & 6 & 1.9 \\
\hline Requires improvement & 62 & 23.1 & 39 & 18.8 & 45 & 22.4 & 71 & 22.2 \\
\hline Good & 191 & 71.0 & 157 & 75.5 & 148 & 73.6 & 233 & 72.8 \\
\hline Outstanding & 10 & 3.7 & 7 & 3.4 & 6 & 3.0 & 10 & 3.1 \\
\hline Region & & al $n=268$ & & al $n=208$ & & $\mathrm{al} \mathrm{n}=202$ & & al $n=320$ \\
\hline & $n$ & $\%$ & $n$ & $\%$ & $n$ & $\%$ & $\mathrm{n}$ & $\%$ \\
\hline East Midlands & 45 & 16.8 & 29 & 13.9 & 29 & 14.4 & 52 & 16.3 \\
\hline East of England & 17 & 6.3 & 12 & 5.8 & 10 & 5.0 & 18 & 5.6 \\
\hline London & 16 & 6.0 & 10 & 4.8 & 8 & 4.0 & 17 & 5.3 \\
\hline North East & 15 & 5.6 & 13 & 6.3 & 15 & 7.4 & 21 & 6.6 \\
\hline North West & 48 & 17.9 & 60 & 28.9 & 42 & 20.8 & 73 & 22.8 \\
\hline South East & 42 & 15.7 & 21 & 10.1 & 36 & 17.8 & 40 & 12.5 \\
\hline South West & 54 & 20.2 & 37 & 17.8 & 42 & 20.8 & 59 & 18.4 \\
\hline West Midlands & 22 & 8.2 & 13 & 6.3 & 10 & 5.0 & 25 & 7.8 \\
\hline Yorkshire and the Humber & 9 & 3.4 & 13 & 6.3 & 10 & 5.0 & 15 & 4.7 \\
\hline Number of SARS-CoV-2 tests performed per LTCF & Mean & SD & Mean & SD & Mean & SD & Mean & SD \\
\hline PCR, staff and residents & 299.3 & 11.1 & 252.8 & $10.3(n=209)$ & 259.3 & $10.6(n=202)$ & 261.1 & 9.5 \\
\hline PCR, staff only & 225.1 & $9.5(n=265)$ & 181.7 & $8.4(n=204)$ & 205.8 & $9.4(n=195)$ & 207.5 & $8.1(n=312)$ \\
\hline PCR, residents only & 79.0 & $3.1(n=268)$ & 75.4 & $3.8(n=209)$ & 61.6 & $2.5(n=199)$ & 61.8 & $2.3(n=313)$ \\
\hline LFD, staff and residents & 10.9 & $1.9(n=71)$ & 181.3 & $11.1(n=202)$ & 247.5 & $12.9(n=200)$ & 219.4 & $9.8(n=309)$ \\
\hline LFD, staff only & 9.9 & $1.8(n=66)$ & 181.2 & $11.1(n=199)$ & 244.9 & $12.7(n=199)$ & 214.9 & $9.5(n=309)$ \\
\hline $\begin{array}{l}\text { SARS-CoV-2 tests performed which were positive } \\
\text { per LTCFe }\end{array}$ & Mean & SD & Mean & SD & Mean & SD & Mean & SD \\
\hline PCR & 2.32 & 0.29 & 3.29 & $0.50(n=209)$ & 0.27 & $0.07(n=202)$ & 0.38 & 0.31 \\
\hline LFD & 0.66 & $0.48(n=71)$ & 1.73 & $0.85(n=202)$ & 0.05 & $0.01(n=200)$ & 0.11 & $0.02(n=309)$ \\
\hline
\end{tabular}


CQC: care quality commission; IQR: interquartile range; LFD: lateral flow device; LTCF: long-term care facilities; PCR: polymerase chain reaction; SARS-CoV-2: severe acute respiratory syndrome coronavirus 2; SD: standard deviation.

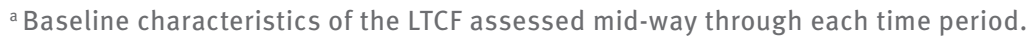

${ }^{\mathrm{b}}$ Median per LTCF, across all LTCF included in the time period (see Supplement).

${ }^{c}$ Median proportion per LTCF, across all LTCF included in the time period.

${ }^{d}$ Mean number of tests performed per LTCF after removal of duplicates, across all LTCF included in the time period when this type of testing was being performed in the LTCF (for example, LTCF with no LFD tests recorded were removed from the denominator).

e Mean proportion of SARS-CoV-2-positive tests per LTCF after removal of duplicates, across all LTCF included in the time period when this type of testing was being performed in the LTCF (for example, LTCF with no LFD tests were removed from the denominator).

Note: The number of LTCF varied for some variables where LTCF information was not available for example, capacity tracker information pertaining to number of residents/staff/dementia beds was not consistently reported and monthly turnover data was not available for all LTCF. Number of LTCFs considered for these variables is supplied in the table in brackets as $\mathrm{n}$.

The study identified a shift towards staff-only outbreaks, possibly associated with lower vaccination coverage in staff vs residents, greater infection risk associated with staff mixing outside of the LTCF, testing policy leading to increased testing of staff compared with residents, or possibly improved protection offered to residents by infection control measures. We also saw the proportion of resident-only outbreaks rising between January and February 2021 and between March and April 2021, although this remained far below the proportion of staff-only outbreaks over the same periods and the subsequent trend did not show an increase in resident-only outbreaks, so the importance appears minimal. Future studies with longer follow-up may explore this further. The higher attack rate in residents compared with staff is augmented by the lower total number of residents per LTCF compared with staff. However, given that more outbreaks affected only staff, similar average absolute numbers of infected staff and residents per outbreak indicate a relatively high number of resident cases in outbreaks that included residents relative to staff cases in outbreaks including staff. Further analysis is required to investigate the association between the larger absolute numbers for residents and LTCF size.

We saw trends in LTCF test positivity that mirrored national incidence rates and, while SARS-CoV-2 continues to circulate, this along with the shift towards staff only outbreaks supports the ongoing need for regular PCR/LFD testing of staff, although this may become less relevant following the introduction of mandatory vaccination of staff [9]. In addition, our findings support a review of resident testing because continuing to test residents regularly is pertinent considering the higher attack rate among residents, despite the shift towards staff-only outbreaks. Indeed, an increase in routine testing of residents may be warranted when community incidence is high to ensure cases are not missed.

Strengths of this study include the large, geographically representative LTCF cohort and access to regular routine $P C R / L F D$ results, increasing the likelihood that outbreaks were correctly identified. Limitations include that, although we reported mortality data, we were unable to report on clinical severity as these data were unavailable. Another limitation is that defining outbreak end dates using testing data is challenging as residents are only tested monthly. Therefore, re-testing more than 28 days after outbreak commencement may be classified as a new outbreak, however, sensitivity analysis showed no substantial difference after extending the outbreak end-date definition. Finally, missing data resulted in numerous LTCFs being excluded during analysis, with the proportion of LTCFs excluded per time-period ranging from $0 \%$ to $82 \%$ across all variables. Further studies should model risk factors influencing the risk and severity of LTCF outbreaks to inform preventative measures to limit LTCF outbreaks.

\section{Conclusions}

This study supports the ongoing national COVID-19 vaccination campaign in LTCF including vaccination of staff. It also supports continuation of testing in this setting while SARS-CoV-2 continues to circulate.

\section{Acknowledgements}

We thank the staff and residents of the LTCF that participated in this study. The views expressed in this publication are those of the authors and not necessarily those of the NHS, Public Health England, or the Department of Health and Social Care.

\section{Conflict of Interest}

LS reports grants from the United Kingdom Department of Health and Social Care during the conduct of the study and is a member of the Social Care Working Group, which reports to the Scientific Advisory Group for Emergencies. All other authors declare no competing interests.

Authors' contributions 
Characteristics of COVID-19 outbreaks in long-term care facilities across four time periods, England, November 2020-June 2021

\begin{tabular}{|c|c|c|c|c|c|c|c|c|}
\hline Characteristics & \multicolumn{2}{|c|}{$\begin{array}{l}\text { Time period } 1 \\
\text { Nov-Dec } 2020\end{array}$} & \multicolumn{2}{|c|}{$\begin{array}{l}\text { Time period } 2 \\
\text { Jan-Feb } 2021\end{array}$} & \multicolumn{2}{|c|}{$\begin{array}{l}\text { Time period } 3 \\
\text { Mar-Apr } 2021\end{array}$} & \multicolumn{2}{|c|}{$\begin{array}{l}\text { Time period } 4 \\
\text { May-Jun } 2021\end{array}$} \\
\hline $\begin{array}{l}\text { Number of } \\
\text { outbreaks }\end{array}$ & \multicolumn{2}{|l|}{145} & \multicolumn{2}{|l|}{114} & \multicolumn{2}{|l|}{23} & \multicolumn{2}{|l|}{15} \\
\hline $\begin{array}{l}\text { Number of LTCF with } \\
\text { outbreaks }\end{array}$ & \multicolumn{2}{|l|}{139} & \multicolumn{2}{|l|}{111} & \multicolumn{2}{|l|}{23} & \multicolumn{2}{|l|}{15} \\
\hline $\begin{array}{l}\text { Number of large } \\
\text { outbreaks per time } \\
\text { period }^{\text {a }}\end{array}$ & \multicolumn{2}{|l|}{31} & \multicolumn{2}{|l|}{9} & \multicolumn{2}{|l|}{0} & \multicolumn{2}{|l|}{0} \\
\hline Proportions & $\%$ & $95 \% \mathrm{Cl}$ & $\%$ & $95 \% \mathrm{Cl}$ & $\%$ & $95 \% \mathrm{Cl}$ & $\%$ & $95 \% \mathrm{Cl}$ \\
\hline $\begin{array}{l}\text { Proportion of LTCF } \\
\text { with outbreaks }\end{array}$ & 51.5 & $45 \cdot 5-57 \cdot 4$ & 52.9 & $46.1-59.6$ & 11.3 & $7.6-16.5$ & $4 \cdot 7$ & $2.8-7.6$ \\
\hline $\begin{array}{l}\text { Proportion of } \\
\text { LTCF with large } \\
\text { outbreaks }^{\mathrm{a}}\end{array}$ & 11.5 & $8.2-15.9$ & $4 \cdot 3$ & $2.2-8.1$ & \multicolumn{2}{|l|}{0} & \multicolumn{2}{|l|}{0} \\
\hline $\begin{array}{l}\text { Proportion of } \\
\text { outbreaks that only } \\
\text { affected residents }\end{array}$ & 9.0 & $5 \cdot 3-14 \cdot 9$ & 7.0 & $3 \cdot 5-13 \cdot 5$ & $17 \cdot 4$ & $6.3-39.7$ & $13 \cdot 3$ & $2.9-44.0$ \\
\hline $\begin{array}{l}\text { Proportion of } \\
\text { outbreaks that only } \\
\text { affected staff }\end{array}$ & 13.8 & $9.0-20.5$ & $19 \cdot 3$ & $13.0-27.7$ & 39.1 & $21.0-60.9$ & $53 \cdot 3$ & $27.4-77.6$ \\
\hline $\begin{array}{l}\text { Proportion of } \\
\text { outbreaks that } \\
\text { affected residents } \\
\text { and staff }\end{array}$ & 77.2 & $69.6-83.4$ & 73.7 & $64.8-81.0$ & 43.5 & $24 \cdot 3-64.8$ & 33.3 & $13.4-61.8$ \\
\hline Characteristics & Mean (SD) & $p$ value & $\begin{array}{l}\text { Mean } \\
\text { (SD) }\end{array}$ & $p$ value & $\begin{array}{l}\text { Mean } \\
(\mathrm{SD})\end{array}$ & $p$ value & $\begin{array}{l}\text { Mean } \\
(\mathrm{SD})\end{array}$ & $p$ value \\
\hline $\begin{array}{l}\text { Number of } \\
\text { outbreaks per LTCF }\end{array}$ & $0.54(0.03)$ & Reference & $\begin{array}{l}0.54 \\
(0.04)\end{array}$ & 0.8403 & $\begin{array}{l}0.11 \\
(0.02)\end{array}$ & $<0.00001$ & $\begin{array}{l}0.05 \\
(0.01)\end{array}$ & $<0.00001$ \\
\hline $\begin{array}{l}\text { Number of large } \\
\text { outbreaks per LTCFa }\end{array}$ & $0.11(0.02)$ & Reference & $\begin{array}{l}0.04 \\
(0.01) \\
\end{array}$ & 0.0047 & 0 & $\mathrm{Na}$ & 0 & $\mathrm{Na}$ \\
\hline $\begin{array}{l}\text { Duration (days) of } \\
\text { outbreak per LTCF }\end{array}$ & $63.0(2.15)$ & Reference & $\begin{array}{l}48.04 \\
(1.46) \\
\end{array}$ & $<0.00001$ & $\begin{array}{l}35.43 \\
(1.47)\end{array}$ & $<0.00001$ & $\begin{array}{l}34.07 \\
(1.43) \\
\end{array}$ & $<0.00001$ \\
\hline $\begin{array}{l}\text { Proportion of } \\
\text { residents who died } \\
\text { of COVID-19 during } \\
\text { an outbreak per } \\
\text { LTCF }^{\text {b }}\end{array}$ & $\begin{array}{l}5.09 \\
(0.68) \\
(n=144)\end{array}$ & Reference & $\begin{array}{l}3.32 \\
(0.67)\end{array}$ & 0.0051 & $\begin{array}{l}0.25 \\
(0.17)\end{array}$ & $<0.00001$ & $\begin{array}{l}0.16 \\
(0.16)\end{array}$ & 0.0001 \\
\hline $\begin{array}{l}\text { Proportion infected } \\
\text { during an outbreak }\end{array}$ & $\begin{array}{l}17.6(1.51) \\
(n=144)\end{array}$ & Reference & $\begin{array}{l}11.0 \\
(1.10)\end{array}$ & 0.0046 & $\begin{array}{l}3.58 \\
(0.74)\end{array}$ & $<0.00001$ & $\begin{array}{l}3.01 \\
(0.68) \\
(n=14)\end{array}$ & $<0.00001$ \\
\hline $\begin{array}{l}\text { Proportion of staff } \\
\text { infected during } \\
\text { outbreak }^{\text {b }}\end{array}$ & $15.6(1.46)$ & Reference & $\begin{array}{l}9.05 \\
(1.14)\end{array}$ & 0.0012 & $\begin{array}{l}2.64 \\
(0.43)\end{array}$ & $<0.00001$ & $\begin{array}{l}3.61 \\
(0.54) \\
(n=14)\end{array}$ & 0.0008 \\
\hline $\begin{array}{l}\text { Proportion of } \\
\text { residents infected } \\
\text { during outbreak }^{b}\end{array}$ & $\begin{array}{l}20.00 \\
(1.87) \\
(n=144) \\
\end{array}$ & Reference & $\begin{array}{l}12.67 \\
(1.47)\end{array}$ & 0.0229 & $\begin{array}{l}4.10 \\
(1.31)\end{array}$ & $<0.00001$ & $\begin{array}{l}6.31 \\
(4.21)\end{array}$ & 0.0002 \\
\hline $\begin{array}{l}\text { Number of } \\
\text { individuals infected } \\
\text { per LTCF outbreak }\end{array}$ & $\begin{array}{l}16.14 \\
(1.39)\end{array}$ & Reference & $\begin{array}{l}8.96 \\
(0.77)\end{array}$ & 0.0039 & $\begin{array}{l}3.30 \\
(0.73)\end{array}$ & $<0.00001$ & $\begin{array}{l}3.13 \\
(0.46)\end{array}$ & $<0.00001$ \\
\hline $\begin{array}{l}\text { Number of staff } \\
\text { infected per LTCF } \\
\text { outbreak }^{\mathrm{b}}\end{array}$ & $7.38(0.67)$ & Reference & $\begin{array}{l}4.04 \\
(0.37)\end{array}$ & 0.0065 & $\begin{array}{l}1.43 \\
(0.19)\end{array}$ & $<0.00001$ & $\begin{array}{l}1.80 \\
(0.24)\end{array}$ & 0.0009 \\
\hline $\begin{array}{l}\text { Number of residents } \\
\text { infected per LTCF } \\
\text { outbreak }^{\mathrm{b}}\end{array}$ & $\begin{array}{l}8.76 \\
(0.80)\end{array}$ & Reference & $\begin{array}{l}4.92 \\
(0.52)\end{array}$ & 0.0054 & $\begin{array}{l}1.87 \\
(0.34)\end{array}$ & $<0.00001$ & $\begin{array}{l}1.33 \\
(0.54)\end{array}$ & 0.0001 \\
\hline
\end{tabular}

CI: confidence interval; COVID-19: coronavirus disease; LTCF: long-term care facilities; Na: not applicable; SD: standard deviation.

a Large outbreak defined as over one third of the LTCF being infected (staff and residents combined).

${ }^{\mathrm{b}}$ Total number of outbreaks analysed varied where total number of residents/staff in a LTCF was not available.

We used the Mann-Whitney test to calculate the $\mathrm{p}$ values and to compare means from time interval specified to mean values between November and December 2020. 
Number of COVID-19 outbreaks per month in long-term care facilities in residents only, staff only or staff and residents, England, November 2020-June 2021

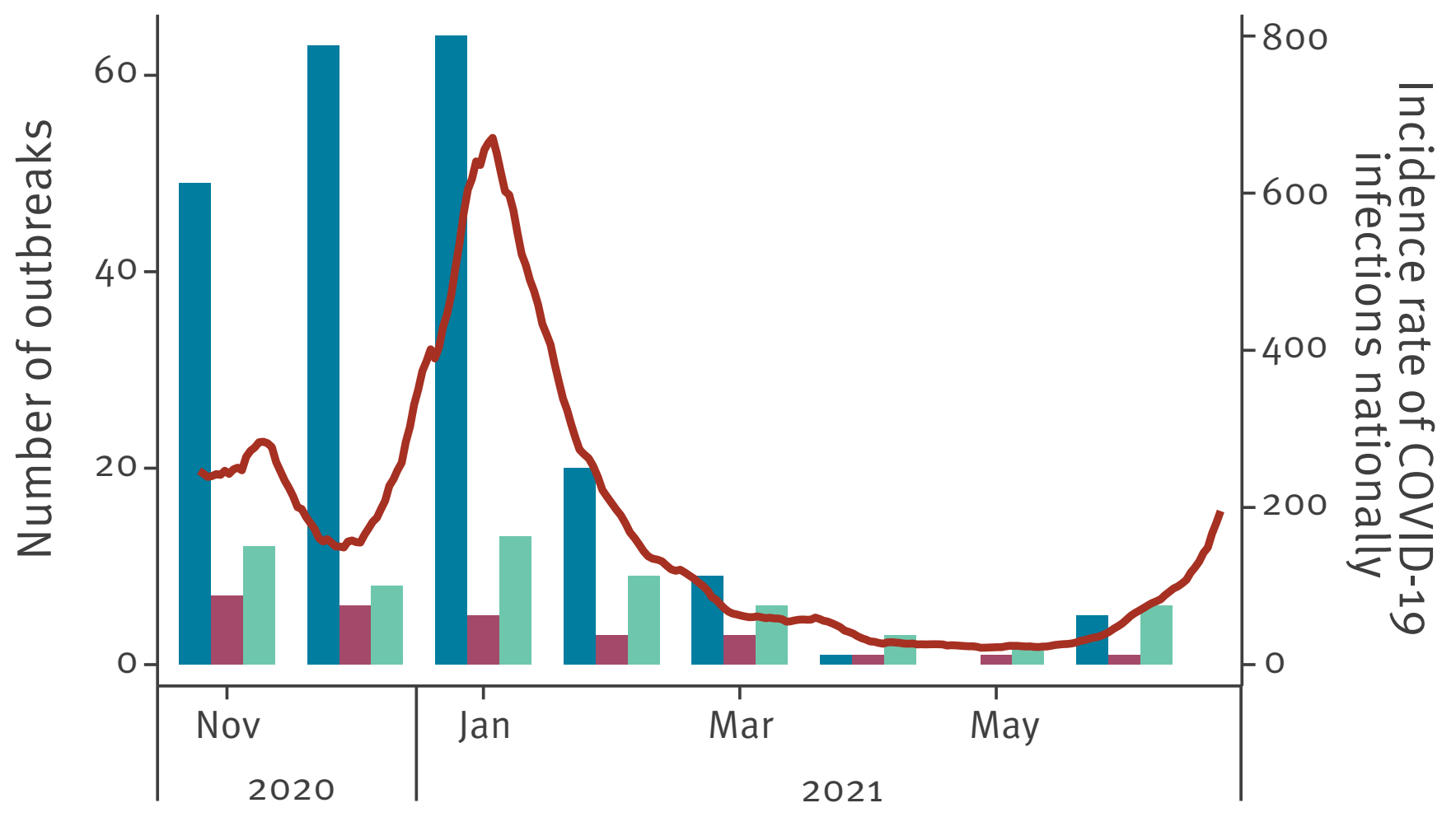

Month

Number of outbreaks among staff and residents

Number of staff-only outbreaks

Number of residents-only outbreaks

_ COVID-19 positive test results nationally 
Proportion of residents-only, staff-only and staff and residents outbreaks in long-term care facilities, England, November 2020-June 2021

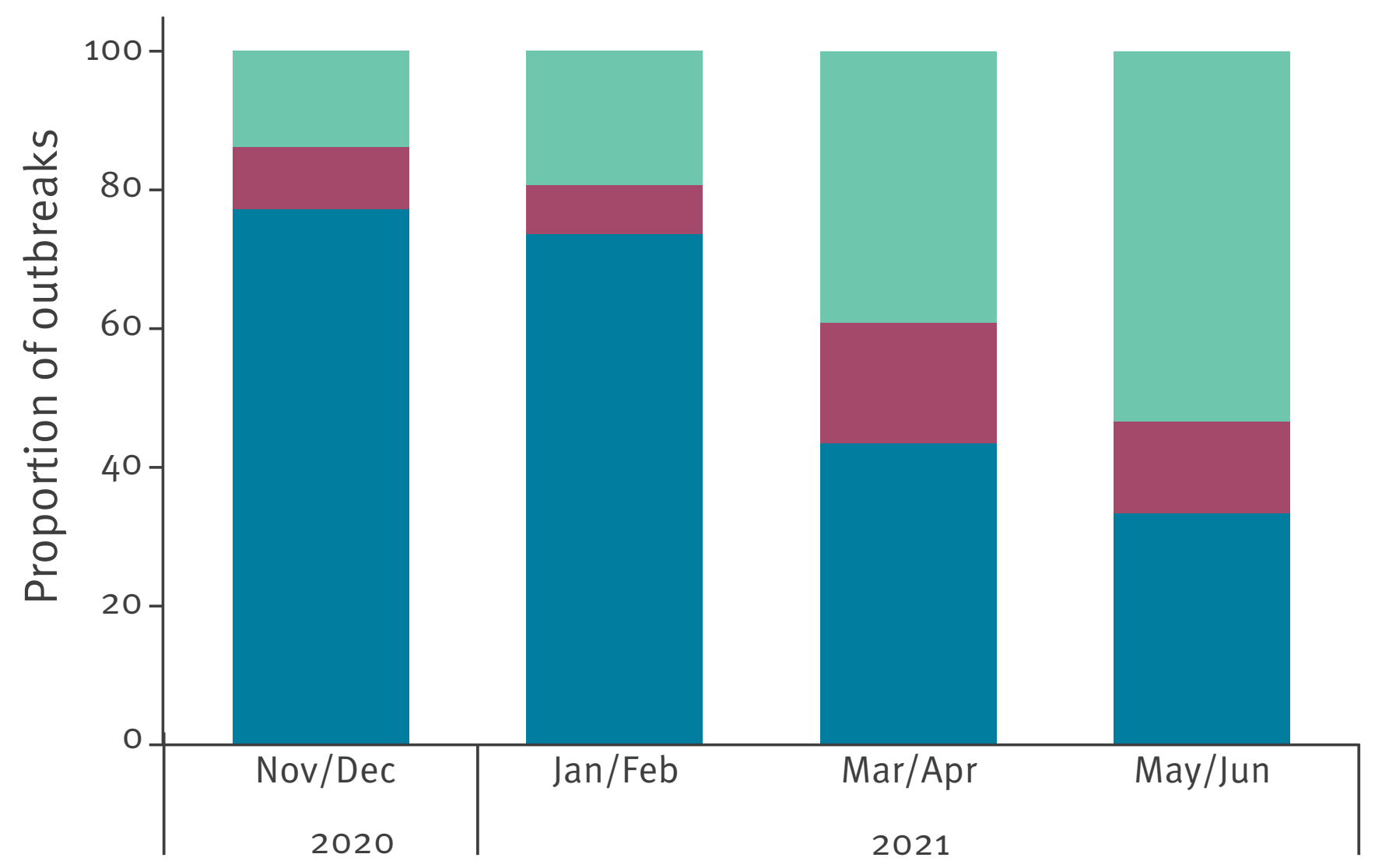

Month

Proportion of outbreaks among staff and residents

Proportion of staff-only outbreaks

Proportion of residents-only outbreaks

COVID-19: coronavirus disease. 


\section{FIGURE 3}

Proportion of residents who died in LTCF and corresponding number of outbreaks during the same time period over successive waves of the COVID-19 pandemic, England, November 2020-June 2021

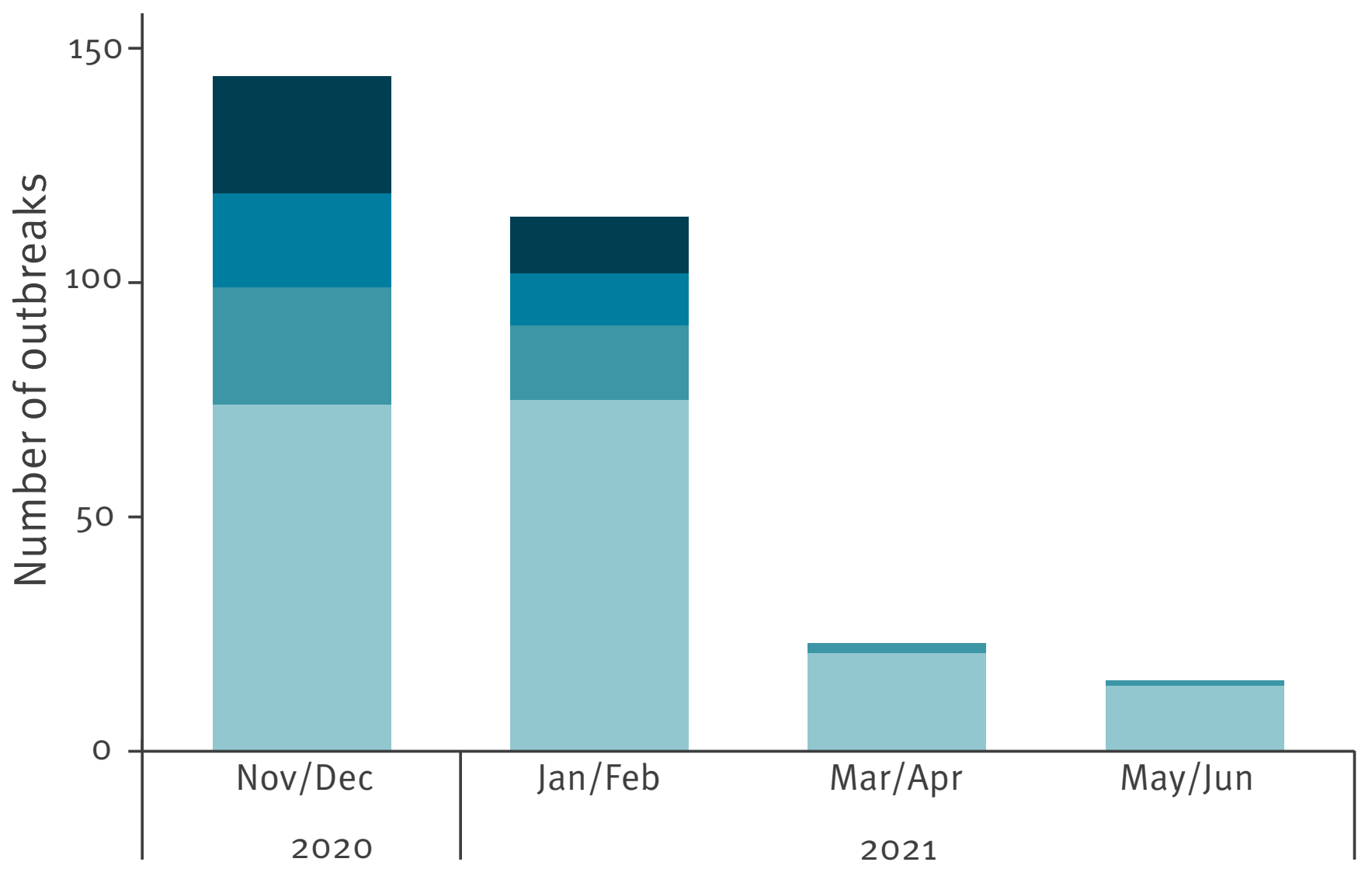

Month

Less than $2 \%$ mortality

$2-5 \%$ mortality
$5-10 \%$ mortality

Over $10 \%$ mortality 
LS, RG and MK conceived the study. RG, TP, MS, and LS devised the statistical methodology. RG did the formal analysis. MK, BA, CF and Al-S were project administrators. LS and $A C$ acquired funding. RG wrote the original draft of the manuscript. All authors reviewed and edited the manuscript. RG, TP, LS and MK had full access to the data in the study. LS has responsibility for the decision to submit for publication.

\section{References}

1. McMichael TM, Currie DW, Clark S, Pogosjans S, Kay M, Schwartz NG, et al. Epidemiology of Covid-19 in a longterm care facility in King County, Washington. N Engl ]

Med. 2020;382(21):2005-11. https://doi.org/10.1056/ NEJMoa2005412 PMID: 32220208

2. Krutikov M, Palmer T, Donaldson A, Lorencatto F, Forbes G, Copas A, et al. Study protocol: understanding SARSCov-2 infection, immunity and its duration in care home residents and staff in England (VIVALDI). Wellcome Open Res. 2021;5:232. https://doi.org/10.12688/ wellcomeopenres.16193.2 PMID: 33564722

3. United Kingdom Government (GOV.UK). Department of Health and Social Care. Transparency data: Coronavirus (COVID-19) testing in care homes: statistics to 8 July 2020. London: GOV.UK; 16 Jul 2020. Available from: https://www.gov.uk/ government/publications/coronavirus-covid-19-testing-in-carehomes-statistics-to-8-july-2020/coronavirus-covid-19-testingin-care-homes-statistics-to-8-july-2020

4. United Kingdom Government (GOV.UK). Department of Health and Social Care. Care home COVID-19 testing guidance: For testing of staff and residents. London: GOV.UK; 2021. Available from: https://assets.publishing.service.gov.uk/government/ uploads/system/uploads/attachment_data/file/1021342/carehome-testing-guidance-england.pdf

5. United Kingdom Health Security Agency (UKHSA). Guidance: COVID-19: epidemiological definitions of outbreaks and clusters in particular settings. London: UKHSA; 2020. Available from: https://www.gov.uk/government/publications/covid19-epidemiological-definitions-of-outbreaks-and-clusters/ covid-19-epidemiological-definitions-of-outbreaks-andclusters-in-particular-settings

6. United Kingdom Government (GOV.UK). Coronavirus (COVID-19) in the UK: download data. London: GOV.UK; 2021. [Accessed: 27 Jul 2021]. Available from: https://coronavirus.data.gov.uk/ details/download

7. Britton A, Jacobs Slifka KM, Edens C, Nanduri SA, Bart SM, Shang N, et al. Effectiveness of the Pfizer-BioNTech COVID-19 vaccine among residents of two skilled nursing facilities experiencing COVID-19 outbreaks - Connecticut, December 2020-February 2021. MMWR Morb Mortal Wkly Rep. 2021;70(11):396-401. https://doi.org/10.15585/mmwr. mm7011e3 PMID: 33735160

8. Shrotri M, Krutikov M, Palmer T, Giddings R, Azmi B, Subbarao $S$, et al. Vaccine effectiveness of the first dose of ChAdOx1 nCoV-19 and BNT162b2 against SARS-CoV-2 infection in residents of long-term care facilities in England (VIVALDI): a prospective cohort study. Lancet Infect Dis. 2021;21(11):152938. https://doi.org/10.1016/S1473-3099(21)00289-9 PMID: 34174193

9. United Kingdom Government (GOV.UK). Department of Health and Social Care. Coronavirus (COVID-19) vaccination of people working or deployed in care homes: operational guidance. London: GOV.UK; 2021. Available from: https:// www.gov.uk/government/publications/vaccination-of-peopleworking-or-deployed-in-care-homes-operational-guidance/ coronavirus-covid-19-vaccination-of-people-working-ordeployed-in-care-homes-operational-guidance

\section{License, supplementary material and copyright}

This is an open-access article distributed under the terms of the Creative Commons Attribution (CC BY 4.0) Licence. You may share and adapt the material, but must give appropriate credit to the source, provide a link to the licence and indicate if changes were made.

Any supplementary material referenced in the article can be found in the online version.

This article is copyright of the authors or their affiliated institutions, 2021. 